\title{
Editorial
}

\section{Dwine Project: The Diversity of Tannins in Italian Red Wines}

\author{
Andrea Versari \\ University of Bologna, Italy
}

*Corresponding author: Andrea Versari, University of Bologna, Italy. E-mail: andrea.versari@unibo.it

Received Date: 19 June, 2018; Accepted Date: 22 October, 2018; Published Date: 20 December, 2018

Dwine project is a network of excellent Italian Universities based on interdisciplinary work team with the aim to expand the current knowledge of research on wine chemistry and sensory, including the ongoing 3-years project on "The diversity of tannins in Italian red wines".

Grape-derived tannins play a key role on red wine chemistry and sensory, contributing to its color, mouthfeel and aroma longevity. Grape contains condensed tannins (also known as proanthocyanidins) that are polymers made of subunits of catechin or epicatechin with a variable degree of galloylation [1] located in berry skins and seeds. During the winemaking process, tannins are extracted into the wine where, through reactions with other metabolites, they undergo complex transformations affecting their chemical and sensory characteristics, including astringency perception in mouth because of the ingestion of wine, arising from precipitation of salivary proteins by wine tannins [2]. However, the intensity and quality of the perceived astringent sensation can vary. Moreover, tannins are also responsible in the perception of undesirable bitterness. Unfortunately, the actual ability of tannins to protect red wine aromas and the related mechanisms and modulating factors, including reactions with anthocyanins, proteins, polysaccharides, remains to be clarified.

With over 300 grape varieties, Italy owns one of the richest ampelographic heritages worldwide. Among these grapes, several examples of varieties extremely rich in tannins are present $[3,4]$ From the marketing point of view, the ability to associate each wine to specific sensory attributes is often a tool for the commercial success. Therefore, a more comprehensive characterization of the tannin characteristics of Italian red wines and an improved ability to manage their extraction and reactions during winemaking would provide a great opportunity to support and consolidate the image of Italian red wines internationally.

In this view, the project aims to provide - by means of tran-

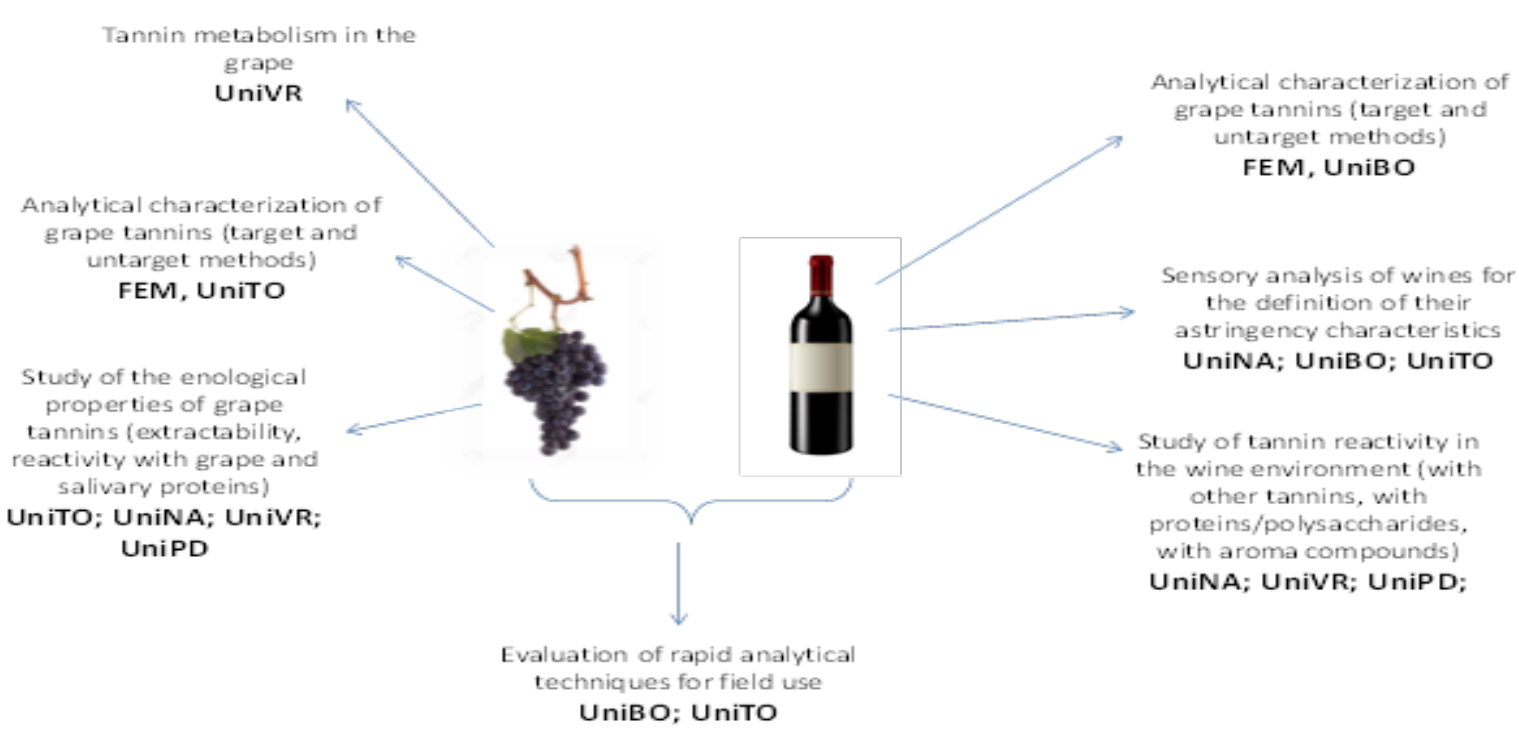

Figure 1: A schematic diagram of the main project areas and the related involvement of the different units. 
scriptional, chemical (targeted and untargeted) and sensory approaches - a full description of the diversity existing among Italian grapes and wines with regard to the biosynthesis, chemical composition and reactivity as well as sensory properties of their tannins figure 1 .

The ultimate goal is to generate, for different Italian red grapes and wines, a database of (i) Compositional information regarding grape/wine tannin and related macromolecules (eg. anthocyanins, SO2, polysaccharides and proteins); (ii) Astringency characteristics of individual grape and wine types, including a specific sensory vocabulary for Italian grapes and wines; (iii) Chemical pathways related to wine aging and involving tannins, in particular with regard to tannin antioxidant protection towards aroma compounds in the specific environment of each wine; (iv) Transcriptomic data concerning tannin biosynthesis in the grape.

Statistical analysis of the datasets obtained (sensory and chemical) will be used to elucidate relationships between tannin composition of each grape/wine and the related sensory and chemical properties.

\section{Acknowledgements}

The project involved five research units (RU), one of which will also include a sub-unit (SU). The research units will be as fol- lows: UniVR (University of Verona); FEM (Fondazione Edmund Mach); UniBO (University of Bologna); UniTO (University of Torino); UniNA (University of Napoli); UniPD (University of Padova).

The teamwork (in alphabetical order; ${ }^{\star}$ National Coordinator): P Arapitsas; A Curioni; A Gambuti; V Gerbi; S Giacosa M Marangon; L Moio; F Mattivi; L Nouvelet; GP Parpinello; D Perenzoni; P Piombino; A Ricci; A Rinaldi; S Río Segade; L Rolle; B Simonato; D Slaghenaufi; G Tornielli; M Ugliano*; A Versari; S Vincenzi.

\section{References}

1. Kennedy JA, Saucier C, Glories Y (2006) Grape and Wine Phenolics: History and Perspective. Am J Enol Vitic 57: 239-248.

2. de Freitas V, Mateus N (2012) Protein/polyphenol interactions: past and present contributions. Mechanisms of astringency perception. Curr Org Chem 16: 724-746.

3. Mattivi F, Zulian C, Nicolini G, Valenti L (2002) Wine, biodiversity, technology, and antioxidants. Ann NYAcad Sci 957: 37-56.

4. Mattivi F, Vrhovsek U, Masuero D, Trainotti D (2009) Differences in the amount and structure of extractable skin and seed tannins amongst red grape varieties. Aust J Grape Wine Res 15: 27-35. 